\title{
Induced resistance: destined to remain on the sidelines of crop protection?
}

\author{
Dale R. Walters
}

Received: 31 July 2009 /Accepted: 28 October 2009/Published online: 18 November 2009

(C) Springer Science + Business Media B.V. 2009

\section{Biography}

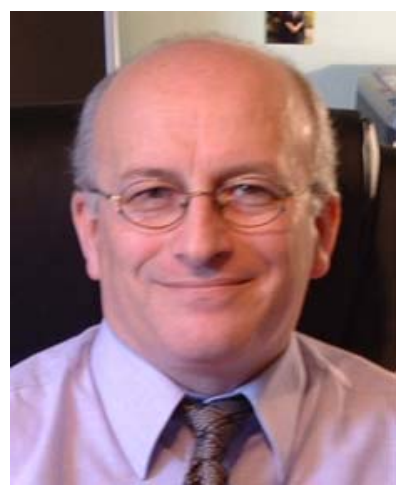

Dale Ronald Walters was born in Tenby in the United Kingdom in 1957 and spent his childhood in Trinidad, West Indies, attending Queen's Royal College from 1969-1975. He obtained a BSc in Plant Science from Wye College, University of London in 1978 and studied for a $\mathrm{PhD}$ at Lancaster University from 1978-1981, under the supervision of Peter Ayres. The $\mathrm{PhD}$ (on root function in powdery mildew-infected barley) was followed by a postdoctoral period at Lancaster working on photosynthesis and nitrogen metabolism in mildew-infected

\section{R. Walters $(\bowtie)$}

Crop and Soil Systems Research Group,

Scottish Agricultural College,

Edinburgh EH9 3JG, UK

e-mail: dale.walters@sac.ac.uk barley. Walters moved to the West of Scotland Agricultural College (later to become part of the Scottish Agricultural College) in August 1982 as a lecturer in plant physiology and immediately started research on physiological responses of diseased plants. This research included much work on polyamine metabolism, as well as work, starting in 1987, on induced resistance. Promotion to senior lecturer in 1990 was followed by appointment as Head of the Department of Plant Biology in 1997. He was elected to a Fellowship of the Institute of Biology in 1998, was awarded a DSc by Lancaster University for his work on host-pathogen physiology in 1999, and was awarded a personal professorship in 2000. He is currently leader of the Plant Pathology Team at the Scottish Agricultural College in Edinburgh, where he is also Manager for Research Postgraduate Studies. Walters has been an Honorary Lecturer at the University of Glasgow since 1985. Publications: 116 refereed publications, plus 136 other publications, edited three books, currently writing a textbook; Senior Editor of Physiological \& Molecular Plant Pathology since 1992, on the Editorial Board of the UK Institute of Biology journal Biologist, and has been on the Editorial Board of Mycological Research and the Italian journal Plant Biosystems. Current research: Induced resistance to plant disease, especially in relation to field implementation; fitness and ecological costs associated with induced resistance; novel approaches to control of plant disease; physiological responses of plants to pathogens. 
Treatment of plants with a variety of agents (e.g. virulent or avirulent pathogens, non-pathogens, cell wall fragments, plant extracts, synthetic chemicals) can lead to the induction of resistance to subsequent pathogen attack, both locally and systemically (Walters et al. 2005). The resistance induced is characterized by a restriction of pathogen growth and a suppression of disease symptom development (e.g. a reduction in lesion size and/or number) compared with non-induced plants infected with the same pathogen (Hammerschmidt 1999). Early research by Joseph Kuć and colleagues (see Kuć 1987) showed that prior inoculation of crop plants (e.g. cucumber with Colletotrichum lagenarium, and tobacco with Peronospora tabacina) provided effective field protection against various pathogens. We now know that induced resistance can be split broadly into systemic acquired resistance (SAR) and induced systemic resistance (ISR). The onset of SAR is associated with an accumulation of salicylic acid (SA) at sites of infection and systemically and with the coordinated activation of a specific set of genes encoding PR proteins, some of which possess antimicrobial activity (Hammerschmidt 1999). Treatment of plants with SA or one of its functional analogs, e.g. acibenzolar-S-methyl (ASM), induces SAR and activates the same set of pathogenesis-related (PR) genes (Hammerschmidt 1999). ISR develops as a result of colonization of plant roots by plant growthpromoting rhizobacteria (PGPR) and is mediated by a SA-independent pathway (Pieterse and Van Loon 2007). Saprophytic rhizosphere bacteria are present in large numbers on plant root surfaces and strains isolated from naturally disease-suppressive soils, mainly Pseudomonas spp., have been shown to promote plant growth by suppressing soilborne pathogens (Pieterse and Van Loon 2007). This activity can be the result of competition for nutrients, siderophore-mediated competition for iron, antibiosis, or secretion of lytic enzymes. Some of these bacterial strains reduce disease through ISR. ISR has been shown to function independently of SA and activation of PR genes, requiring instead jasmonic acid (JA) and ethylene. ISR is not associated with increases in expression of known defense-related genes, but following challenge with a pathogen, plants expressing ISR exhibit an enhanced expression of certain JAresponsive genes (Pieterse and Van Loon 2007). Another feature of induced resistance that is common to both SAR and ISR is a phenomenon called priming, whereby plant defenses are not directly activated by the inducing agent but instead are potentiated for enhanced expression upon subsequent pathogen attack (Beckers and Conrath 2007). As pointed out by Hammerschmidt (2007), because the phenotypes of SAR and ISR are similar, if not identical, in terms of reducing the effects of pathogen challenge, caution should be exercised when attempting to distinguish between ISR and SAR in plantpathogen systems that are not as well characterized as those involving Arabidopsis.

Induced resistance offers the prospect of broad spectrum disease control using the plant's own resistance mechanisms and, as a result, there has been great interest in the development of agents which can mimic natural inducers of resistance. These include elicitor molecules released during the early stages of the plant-pathogen interaction, the signaling pathways used to trigger defenses locally and systemically, and the use of PGPR. Examples include acibenzolar-Smethyl (ASM), probenazole, $\beta$-aminobutyric acid (BABA), oligosaccharides from plant and fungal cell walls, and certain strains of PGPR. Close examination of these agents reveals that the efficacy of induced resistance in the field is variable, with levels of disease control ranging from $4 \%$ to greater than $90 \%$ (Vallad and Goodman 2004; Walters et al. 2005). This variability in efficacy is a serious impediment to the practical use of induced resistance and demands some explanation of the underlying mechanisms. Induced resistance is a complex plant response to pathogen attack and as such, will be modified by many factors including genotype and environment.

Perhaps surprisingly, little is known about the influence of genotype on induced resistance. Work using the synthetic chemical 2,6-dichloroisonicotinic acid showed that greatest protection against powdery mildew on cucumber was obtained in partially resistant cultivars (Hijwegen and Verhaar 1994). Cultivar-dependent differences in the expression of induced resistance have also been reported in other systems, e.g. soybean (Dann et al. 1998).

Ayres (1984) reviewed the interaction between stress and plant disease and proposed two possible outcomes of the interaction: (i) the possibility that the negative effects of pathogens and abiotic stress might be additive and that (ii) abiotic stress might alter plant resistance to pathogen infection. Indeed, water stress 
has been reported to enhance resistance to powdery mildew in barley (Ayres 1984).

It has been suggested that induced resistance is associated with costs to the plant, for example, a diversion of resources away from plant growth towards defense (Walters and Heil 2007). If so, it seems reasonable to suggest that any constraints on the availability of such resources should affect the expression of induced resistance. Indeed, the magnitude of costs associated with induced resistance was found to be dependent on environmental conditions, including nitrogen, water stress and inter-plant competition (Dietrich et al. 2005). However, not all studies have found an effect of nitrogen on the efficacy of induced resistance. Wiese et al. (2003) could find no effect of nitrogen on resistance induced by ASM against powdery mildew on barley in field trials. Instead, they found that resistance induced by ASM was most profoundly affected by the organic matter content of the soil, with soils containing low organic matter content exhibiting the greatest induction of resistance. The authors suggested that high microbial activity in soils with high organic matter content may have led to a high degree of resistance, possibly induced by rhizobacteria and which could not be further enhanced by ASM (Wiese et al. 2003). In soils with low organic matter content and hence low microbial activity, any rhizobacteria-induced resistance would be much less, allowing ASM-induced resistance to be expressed.

Importantly, although direct induction of resistance has been reported to incur costs to plants, priming plant defenses has been shown to provide yield benefits, particularly under disease pressure (Van Hulten et al. 2006; Walters et al. 2009). Based on such evidence, priming might, therefore, be more appropriate for practical disease control than direct induction of resistance.

Induced resistance has the potential to revolutionize disease control in crops. And yet, after decades of research, induced resistance still sits outside mainstream crop protection. Why? The answer lies in much of what has been presented above. It is inconsistent, providing high levels of disease control in some situations but not others, and it rarely provides levels of control that can be achieved with modern fungicides. Are we asking too much of induced resistance? Farmers and growers have come to expect very high levels of disease control provided by fungicides. However, agriculture is changing, as are public expect- ations of, and attitudes toward, agriculture. There is increasing concern for the environment and as a result a desire to reduce pesticide use. There is also the everpresent problem of fungicide resistance. There are also many crop-pathogen interactions for which there are no effective control measures. Viewed from this perspective, induced resistance could be useful. So what needs to be done in order to move induced resistance from the sidelines and into mainstream crop protection?

There is a real need for information on, and understanding of, the effects of genotype and environment on the expression of induced resistance and its efficacy in the field. It is also important to recognize that under field conditions, plants will already be induced to a degree, and this might affect the extent to which resistance can be further enhanced (Walters 2009). Although it is possible that induced resistance could be used on its own to control certain diseases, for which no other effective control exists, it is more likely that induced resistance will be incorporated into crop protection programs. However, this will require information on how best to fit it into existing programs for particular crops and diseases. There is much work demonstrating the effectiveness of combining fungicides and agents that elicit induced resistance, either alternating their use in the same program or applying them together (see Vallad and Goodman 2004). Combined use of induced resistance and fungicides should extend the effectiveness and lifespan of fungicides. This will require a much better understanding of the effect of induced resistance on pathogen population biology.

Although a great deal is known about the mechanisms underlying resistance induced by prior inoculation with necrotizing pathogens and use of plant activators like ASM, much less is known (and in some cases nothing is known) about the mechanisms underlying resistance induced by other agents. This is an important area for future work, which will be greatly aided by developments in gene array technologies. By understanding the pathways activated and resistance mechanisms triggered by different agents, it should be possible to use cocktails of elicitors to provide effective and reliable protection.

Acknowledgments SAC receives financial support from the Rural Environment Research and Analysis Directorate of the Scottish Government. 


\section{References}

Ayres, P. G. (1984). The interaction between environmental stress injury and abiotic disease physiology. Annual Review of Phytopathology, 22, 53-75.

Beckers, G. J., \& Conrath, U. (2007). Priming for stress resistance: from the lab to the field. Current Opinion in Plant Biology, 10, 425-431.

Dann, E., Diers, B., Byrum, J., \& Hammerschmidt, R. (1998). Effect of treating soybean with 2, 6-dichloroisonicotinic acid (INA) and benzothiadiazole (BTH) on seed yields and the level of disease caused by Sclerotinia sclerotiorum in field and greenhouse studies. European Journal of Plant Pathology, 104, 271-278.

Dietrich, R., Ploss, K., \& Heil, M. (2005). Growth responses and fitness costs after induction of pathogen resistance depend on environmental conditions. Plant Cell and Environment, 28, 211-222.

Hammerschmidt, R. (1999). Induced disease resistance: how do induced plants stop pathogens? Physiological and Molecular Plant Pathology, 55, 77-84.

Hammerschmidt, R. (2007). Introduction: definitions and some history. In D. Walters, A. Newton \& G. Lyon (Eds.), Induced resistance for plant disease control: A sustainable approach to crop protection (pp. 65-88). Oxford, UK: Blackwell.

Hijwegen, T., \& Verhaar, M. A. (1994). Effects of cucumber genotype on the induction of resistance to powdery mildew. Plant Pathology, 44, 756-762.

Kuć, J. (1987). Plant immunization and its applicability for disease control. In I. Chet (Ed.), Innovative approaches to plant disease control (pp. 255-272). New York, NY: Wiley.

Pieterse, C. M. J., \& Van Loon, L. C. (2007). Signalling cascades involved in induced resistance. In D. Walters, A. Newton \& G. Lyon (Eds.), Induced resistance for plant disease control: A sustainable approach to crop protection (pp. 65-88). Oxford, UK: Blackwell.

Vallad, G. E., \& Goodman, R. M. (2004). Systemic acquired resistance and induced systemic resistance in conventional agriculture. Crop Science, 44, 1920-1934.

Van Hulten, M., Pelser, M., Van Loon, L. C., Pieterse, C. M. J., \& Ton, J. (2006). Costs and benefits of priming for defense in Arabidopsis. Proceedings of the National Academy of Sciences, USA, 103, 5602-5607.

Walters, D. R. (2009). Are plants in the field already induced? Implications for practical disease control. Crop Protection, 28, 459-465.

Walters, D. R., \& Heil, M. (2007). Costs and trade-offs associated with induced resistance. Physiological and Molecular Plant Pathology, 71, 3-17.

Walters, D. R., Walsh, D., Newton, A. C., \& Lyon, G. D. (2005). Induced resistance for plant disease control: maximising the efficacy of resistance elicitors. Phytopathology, 95, 1368-1373.

Walters, D. R., Paterson, L., Walsh, D. J., \& Havis, N. D. (2009). Priming for plant defense in barley provides benefits only under high disease pressure. Physiological and Molecular Plant Pathology, 73, 95-100.

Wiese, J., Bagy, M. M. K., \& Schubert, S. (2003). Soil properties, but not plant nutrients $(\mathrm{N}, \mathrm{P}, \mathrm{K})$ interact with chemically induced resistance against powdery mildew in barley. Journal of Plant Nutrition and Soil Science, 166, 379-384. 